Review Article

\title{
Strong Far-Field Vertical Excitation and Building Damage: A Systematic Review and Future Avenues
}

\author{
Dipendra Gautam (iD ${ }^{1,2,3,4}$ and Rewati Baruwal ${ }^{2}$ \\ ${ }^{1}$ Department of Civil Engineering, Cosmos College of Management and Technology, Lalitpur, Nepal \\ ${ }^{2}$ Interdisciplinary Research Institute for Sustainability, IRIS, Kathmandu, Nepal \\ ${ }^{3}$ Department of Civil Engineering, Institute of Engineering, Thapathali Campus, Kathmandu, Nepal \\ ${ }^{4}$ Nepal Academy of Science and Technology, Lalitpur, Nepal \\ Correspondence should be addressed to Dipendra Gautam; dipendra01@tcioe.edu.np
}

Received 21 May 2020; Revised 14 July 2020; Accepted 20 March 2021; Published 30 March 2021

Academic Editor: Jian Ji

Copyright ( 2021 Dipendra Gautam and Rewati Baruwal. This is an open access article distributed under the Creative Commons Attribution License, which permits unrestricted use, distribution, and reproduction in any medium, provided the original work is properly cited.

\begin{abstract}
Strong vertical excitation may lead to detrimental consequences on structures and infrastructures. To date, the impacts of strong vertical shaking on structures and infrastructures are considered for near-field regions only. However, anomalies in terms of recorded evidence and damage occurrence in the central Himalayan earthquakes dragged the attention of the researchers to explore the possibility of strong vertical shaking in far-field regions as well. Systematic review approach is used to sum up the findings from scholastic works reported to date and juxtaposed the findings with the evidence from central Himalayan earthquakes. It is concluded that the strong vertical shaking in the far-field is undeniable, at least in the central Himalayas; thus, incorporation of strong far-field vertical shaking in structural analysis and design is required. This paper reports the evidence reported in the literature for strong vertical shaking and adds evidence from Nepal focusing on strong far-field vertical excitation.
\end{abstract}

\section{Introduction}

With an increasing availability of accelerometric records, experimental and numerical studies on the effects of strong vertical excitations are appearing more frequently nowadays. Although moderate to strong earthquakes rarely occur and instrumentation is not adequate across the active seismic regions, the impacts of vertical excitations were surfaced mainly after 1990s. For many years, vertical shaking is considered to be significant in the near-field regions only. Possibly, due to the fact that the effects would be detrimental in the near-field regions, consideration of vertical excitation in near-field regions deemed necessary. Many researchers conducted analyses on the seismic behavior of several types of structures considering the near-field strong motion records (e.g., [1-6], among others). In high-frequency scenario, the vertical-to-horizontal spectral ratio would be greater than $2 / 3$, which is commonly considered [7], even for source to site distance up to $40 \mathrm{~km}$ [8]. Meanwhile, the V/H ratio would be smaller than $2 / 3$ for a long period as reported by several researchers (see, e.g., [9-11], among others). Several earthquakes worldwide depict that strong vertical shaking in the near-field would be detrimental in terms of structure and infrastructure damage [12-16]. As all the historical evidences coincide with the fact that the strong vertical shaking is prevalent in near-field regions, experimental as well as numerical studies on the effect of vertical excitation on structures and infrastructures are also limited to near-field regions. To the best of authors' knowledge, the far-field strong vertical shaking has not gotten adequate attention although there are some remarkable shreds of evidence to support this aspect. To this end, systematic review was conducted on the effect of strong vertical shaking on buildings to shed light on the necessity of strong far-field shaking pertaining to the recorded and descriptive evidence of the occurrence of strong or strongest vertical excitation in the far-field. This paper aims to report the effect of vertical excitation through extensive literature review and to propose 
a new dimension of the promising research field in the future.

\section{Methodology}

The systematic review approach is used in this study to identify and synthesize the findings of published works that emerged in the past decades. Further details regarding the systematic review approach could be found elsewhere (see, e.g., [17]). The schematic diagram of the systematic review approach is shown in Figure 1. The first step involves the formulation of the pertinent research question(s). In this study, research questions were postulated as follows: is strong vertical excitation significant in far-field too? Thereafter, we explored repositories such as Scopus, Mendeley, ScienceDirect, ASCE Library, Taylor and Francis Online, Wiley Online, Springer, Sage, ResearchGate, and Google. The keywords such as "vertical shaking," "vertical excitation," "far-field motion," "near-field motion," "structure damage," and "building damage" among others were used to identify the potential works for literature review. Apart from the scholastic works, relevant codes and research works related to data and evidence for strong vertical shaking in near field were collected. In total 211 documents were prepared for initial assessment. Thereafter, initial screening was performed considering the quality of publication and publishers, indexation, duplication, and novelty of the works. After a thorough quality assessment, 118 documents from indexed journals, codes, data papers, reviewed reports, and reputed conferences papers were segregated. The papers from indexed journals, reviewed reports, and reputed conferences were used to perform an exhaustive literature review. It should be noted that our scope is limited to building damage due to strong vertical shaking; thus, infrastructure damages are not duly accounted. Thus, seismological aspects of strong vertical shaking and studies related to the effects of vertical shaking on bridges are not reported exhaustively, rather recognized only. The papers selected for review were screened to check the research alignment per our objective, and synopsis of findings from each reviewed content is presented. Critiques on existing studies are then delineated, and future insights and conclusions are formulated attributing the recent observations on far-field vertical shaking. The central Himalayan earthquakes were considered as the evidence to extend state-of-the-art practice to a new direction.

\section{Effects of Vertical Shaking on Structures}

One of the pioneering contributions in the effect of vertical shaking was made by Papazoglou and Elnashai in 1996 [18]. They critically analyzed the damages caused by the Kalamata, Greece, earthquake (1986) for the near-field damage analysis. They further noted that the historical earthquakes such as Skopje (1963), Managua (1972), Thessaloniki (1978), El-Asnam (1980), San Salvador (1986), and Spitak (1989) reflected the possibility of strong vertical shaking in the near-field regions. The Kalamata earthquake showed the V/ $\mathrm{H}$ ratio up to 1.26 (for details, see $[19,20]$ ) as reported by
[18]. Due to strong vertical shaking, the horizontal displacement of items had occurred without visible evidence of friction at the interface. Papazoglou and Elnashai [18] also presented field evidence of horizontally cracked reinforced concrete (RC) pedestal at midheight due to possible tensile action. Reports presented by several researchers (e.g., [20-24]) outlined the unusually high number of symmetric compression and shear-compression failures in columns and shear walls even in soft-story buildings. This evidence was not per the general expectation of the occurrence of bending failure; thus, researchers noted that strong vertical shaking would have been responsible for anomalous damage mechanisms. The soft-story construction is considered to have vulnerability concentrated to ground story, and occurrence of damage is generally expected due to formation of plastic hinges. The soft-story damage, strengthening, and seismic performance aspects are reported elsewhere (see, e.g., $[25,26])$. Papazoglou and Elnashai $[18]$ concluded that the discrepancy of vertical force was responsible for the reduction in shear strength due to loss/reduction of concrete contribution. Papazoglou and Elnashai [18] also presented the evidence of the 1994 Northridge and 1995 Hyogo Ken Nanbu earthquakes citing evidence of unusually strong vertical shaking and damage occurrence in modern buildings.

Several analytical investigations considering the effects of vertical shaking on buildings confirmed that varieties of buildings observe the same level of dynamic amplification due to vertical shaking as reported by Papazoglou and Elnashai [18] and analytical evidence presented by Georgantzis [27], Papadopoulou [28], Papaleontiou and Roesset [29], and Fardis [30]. The analysis conducted by Papadopoulou [28] highlighted that moment-resisting reinforced concrete (RC) frames show the variation of the vertical-tohorizontal fundamental period between 7 and 2.5 for 8 - to 1 -storied buildings. The analysis performed by Georgantzis [27] suggested that the behavior modification factor would be reduced by up to $30 \%$ when considering vertical excitation even though the $\mathrm{V} / \mathrm{H}$ ratio is constrained to $2 / 3[31,32]$. Thus, consideration of vertical motion would result in the failure of the upper story(s). Papazoglou and Elnashai [18] concluded that column shear failure would be the governing factor for the ultimate response when the vertical component is included in analyses. Analysis of steel frame building by Broderick et al. [33] showed that the inclusion of vertical shaking did not affect the interstory drift; however, a $12 \%$ increase in column rotation ductility demand was prevalent due to the occurrence of lower yield rotation. The beam would be the most affected due to vertical shaking. In 1996, Papazoglou and Elnashai [18] shed light on the necessity of inclusion of vertical excitation in earthquake-resistant designs and analyses. However, a broad literature review reflected that the topic is still vital to be explored even after 25 years. Elnashai and Papazoglou [34] presented a method to assess the behavior of RC buildings subject to vertical shaking deploying piecewise linear relationship. They derived bilinear and inelastic spectra and concluded that the net tensile forces and displacement may lead to the reduction in the shear resistance of RC columns. They proposed a modal 


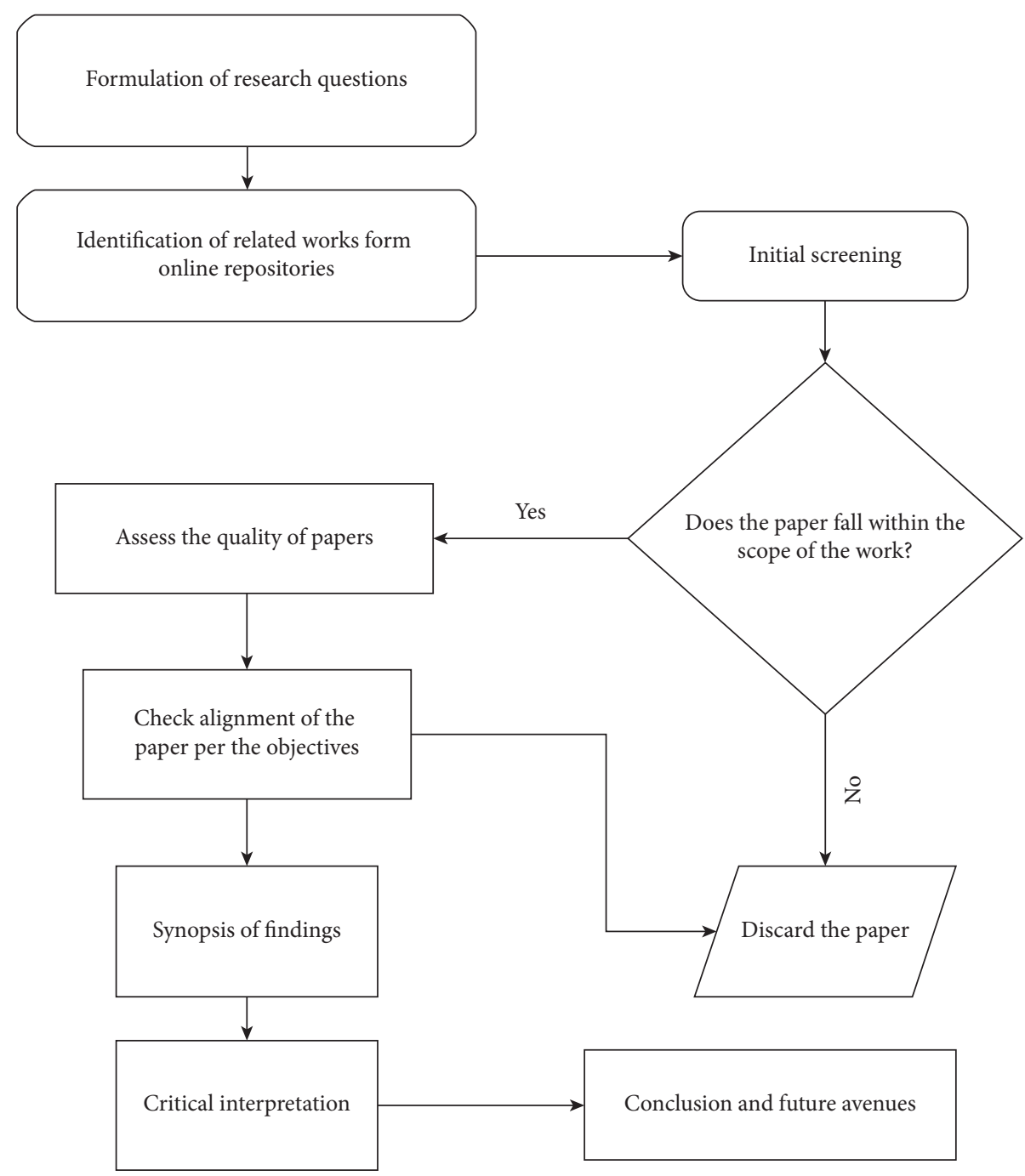

Figure 1: Systematic review approach implemented in the study.

analysis approach that could be deployed to estimate the vertical shaking forces. Their analysis highlighted that vertical excitation could lead to compression failure despite the safety factor for the fundamental load be in the range of 2.5. Ghobarah and Elnashai [35] presented the analysis in the contribution of vertical shaking on the seismic behavior of $\mathrm{RC}$ building considering low- and medium-rise RC buildings. They concluded that the vertical excitation would significantly affect the seismic performance of RC buildings. The vertical excitation was responsible for damage of existing nonductile RC moment-resisting frame building as well as the well designed RC building. The effect on drift was not severe when P- $\Delta$ effects become dominant. They further highlighted that $10-20 \%$ additional strength loss was attributed to the effects of vertical excitation. Similarly, the response modification factor was decreased by $30 \%$ when vertical excitation was accounted for. They reiterated that the near-field vertical shaking would lead to significant damage to the RC buildings.

In 2000, Diotallevi and Landi [36] presented an analysis of the vertical excitation in seismic response of a five-storied
RC frame building using several strong motion records. They compared the response of building with and without the vertical excitation and concluded that the vertical shaking would be detrimental due to the adverse effects in column behavior. They further presented that the vertical excitation would lead to considerable fluctuations in the axial force, and hence the column behavior would be anomalous leading to a significant variation in global structural response. A greater roof displacement was prevalent, and the number of plasticized regions was greater in the columns. Significant reduction in the ductility was responsible for high axial compression, and the momentcurvature loops had become more random, and the greater axial force was responsible for greater peak values of moment and shear. Elgamal and $\mathrm{He}[8]$ denoted that the $\mathrm{V} / \mathrm{H}$ response spectra would be strongly dependent on period and source to site distance and further concluded that the commonly used $\mathrm{V} / \mathrm{H}$ ratio of $2 / 3$ would be too conservative at high frequencies for up to $40 \mathrm{~km}$ source to site distance. They concluded that significantly high frequency $(\geq 8 \mathrm{~Hz})$ was prevalent in vertical excitations. However, their review 
and analysis are more focused on seismological aspects rather than impacts of strong vertical shaking on buildings. Similar seismological studies regarding the strong vertical shaking in near-field regions are also performed by several researchers (see, e.g., [37-44]). Mazza and Vulcano [45] performed analysis on the effects of combined vertical and horizontal components of near-fault ground motions in the nonlinear dynamic response of the base-isolated building. They concluded that the compressive force exceeded the corresponding load for balanced failure in all the stories except the top. Loghman et al. [46] assessed the performance of base-isolated structures mounted on a triple concave friction pendulum (TCFP) bearing deploying the vertical excitation and concluded that the maximum error in calculating the base shear of structure would be $29.5 \%$. They pointed out that if vertical excitation is not considered for superstructure with $<0.6 \mathrm{sec}$ period, the base shear would be underestimated. They further remarked that the inclusion of the vertical component is also critical in practical designs. Dana et al. [47] presented a comparative study considering code-based pseudo-static vertical excitation and nonlinear response history analysis which considers vertical ground excitation for a whole steel frame building and several 2D steel frame buildings. They concluded that the conventional code-based approach would give rise to conservative results as this underestimates the interior column compression demands by up to $40 \%$ with an average of $\sim 20 \%$. Similarly, the moments at the face of the columns were $65 \%$ greater than those for the code-based approach, and the magnitude difference was greater for upper stories when compared with the lower ones. Di Sarno et al. [48] performed finite element analysis of RC frame buildings using the recorded ground motions of the L'Aquila earthquake and concluded that the combination of horizontal and vertical ground motion is required for reliable seismic performance assessment. They highlighted the need for experimental and numerical assessment campaigns to rectify the mechanical models to evaluate the shear capacity of structural members. Mazza and Vulcano [49] and Mazza [50] depicted that the base isolators would sustain tensile loads under vertical excitation of the near-field earthquake. The consequence of such tensile loads may lead to the failure of the base isolation system due to large displacement. Recognizing the role of vertical seismic excitation in the modification of the axial stresses in masonry, Rinaldin et al. [51] performed nonlinear analyses of masonry structures to depict the lateral load resistance of masonry piers. They concluded that the inclusion of the vertical component may lead to an increase in demand/ capacity ratio by an average value of $15 \%$ for the masonry piers. Liberatore et al. [52] performed the finite discrete element model of a masonry structure using recorded accelerograms. They concluded that vertical excitation induces more intense failures in masonry structures with small cohesion due to high-frequency content of the vertical shaking compared with the horizontal one. Elhifnawy et al. [53] considered four analysis schemes, viz., one horizontal component, two horizontal components, one horizontal and the vertical components, and two horizontal and the vertical components and found that the multiple components of the earthquake significantly affect the axial forces and strain ductility factors of the columns. Meanwhile, the effect would not be considerable in terms of lateral deformation response. Abdollahiparsa et al. [54] analyzed the effects of vertical excitation considering soil-structure interaction in steel frame buildings. They concluded that the vertical excitation when combined with the soil-structure interaction effect may increase the axial force on columns by $\sim 50 \%$, maximum vertical displacement on beams by twofold, and story drift by $\sim 40 \%$. Asgarian et al. [55] performed nonlinear dynamic analysis of three moment-resisting frame buildings considering 15 recorded near-field accelerograms. They concluded that the vertical excitation does not significantly affect the dynamic response of the structure in the elastic range; however, they noted remarkable variation in the nonlinear range. Kim et al. [56] depicted that shear failure would be random when vertical excitation is considered in analyses. Wang et al. [57] obtained time histories of bending moment and shear capacities using numerical modeling and demonstrated that vertical excitation would affect both capacities due to high frequency and significant amplification leading to premature failure or anomalous failure modes and casted doubt in the use of capacity design approach. The shifting of brittle shear failure from ductile failure mode due to considerable variation in axial force and presence of tension in piers under near-field ground shaking was revealed by Hosseinzadeh [58] using numerical modeling and by Lee and Mosalam [59] using experimental approach.

As highlighted by Anderson and Bertero [60], seismic demand would increase in the case of coupling the horizontal and vertical components of strong ground motion due to increased lateral forces and P- $\Delta$ effects. Thus, many researchers felt the need for coupling the horizontal and vertical components of earthquakes to predict more realistic behavior. Ju et al. [61] proposed a methodology to perform three-dimensional dynamic analysis of buildings considering vertical excitation. They propose that four fundamental considerations such as division of the main girder into two elements, inclusion of secondary beams, avoidance of floor stiffness if the floor is too thick, and the use of $80 \%$ vertical effective mass led to precise results. With 1080 time-history analyses and 180 static analyses, they concluded that the relationships of extreme column axial forces and beam moments between vertical excitation and dead loads would be linearly proportional to the maximum acceleration taken from the response spectrum for the first vertical frequency. The method proposed by Collier and Elnashai [62] facilitates estimating the structural response under coupled vertical and horizontal components of strong ground motion. Gulerce and Abrahamson [63] and Gulerce et al. [64] developed and implemented the probabilistic seismic demand model and probabilistic seismic hazard assessment procedures to incorporate the randomness of strong ground motion and variation in structural characteristics. They also proposed that the ratio of vertical to horizontal motion would serve as the intensity measure for probabilistic seismic demand models. The study by Warn and Whittaker [65] highlighted that the direct sum of the peak axial forces 
(vertical) that would be induced by the vertical excitation and overturning moment would overestimate the actual axial force on bearing. To this end, Wei et al. [66] highlighted that the simplified approaches may be effective in the estimation of seismic demands of structures but fail to incorporate the variation in moment capacity, shear capacity, and ductility related to the interactions of horizontal and vertical excitations. Recognition of vertical excitation led damages has also emerged after significant earthquakes as reported by Augenti and Parisi [67], Gautam and Chaulagain [68], Kim and Elnashai [69], Bovo et al. [70], Nadim et al. [71], and others. However, the majority of forensic interpretations and damage analyses lack explicit evidence regarding the effects of vertical shaking on structures. Meanwhile, Ambraseys and Simpson [11] and Kale and Akkar [72] have proposed vertical spectra for Europe. Ercolino et al. [73] performed forensic analysis and numerical modeling to assess the causes of roof damage during the Emilia-Romagna earthquake and justified that the collapse of roof elements was attributed to the vertical component of earthquake in the near-field region. Due to the occurrence of considerably large vertical excitation, high relative displacement and low frictional resistance were noted as uplift phenomena in nonlinear dynamic analysis considered by the authors. The effect of three components of earthquake excitation could be in particular more influential for low period structures with sliding support [74]. Similarly, Liauw et al. [75] highlighted that the vertical response of structure is the function of frictional stress that is governed by the supporting element on the foundation pad. They concluded that the inclusion of vertical excitation contributes in the sliding system. Similarly, Lin and Tadjbakhsh [76] confirmed that the vertical excitation can in particular affect the foundation system that is harmonically excited. The high-frequency content associated with the early period excitation due to vertical component of strong motion was reflected in several numerical studies (e.g., [51, 77-84]). Kim et al. [84] performed numerical studies of $13 \mathrm{RC}$ buildings considering the effects of strong vertical shaking. With the variation of vertical-to-horizontal PGA ratio, they studied the effects on vertical excitation on axial force, shear capacity, and shear demand of RC columns. They finally concluded that the vertical excitation leads to the variation in axial force and shear capacity so that vertical excitation cannot be left behind for the purpose of seismic assessment and design of RC buildings. Tian et al. [83] concluded that the effect of vertical ground shaking will not be significant when considering interstory drift as a performance parameter; however, punching failure will dominantly occur, which is seldom expected in horizontal excitations only. They highlighted that the punching failure will reduce the lateral drift capacity by $23 \%$. Lu et al. [85] conducted shake table testing of suspended ceilings. They observed the occurrence of damage to suspended ceilings due to both horizontal and vertical excitations. The experimental campaign concluded that damage to suspended ceilings is not governed by the horizontal shaking. On the contrary, the vertical shaking significantly contributed to the failure of the suspended ceiling-frame system [85]. Hosseini and
Nezamabadi [86] studied the vertical response of Iranian steel buildings considering three-, four-, and five-storied steel buildings. Scenario analyses performed considering the vertical excitation and without considering it resulted considerable variation in compression and tension leading to noticeable uplift. They further justified that the effects of vertical shaking will be more pronounced in moment frames rather than the bracing members. The authors numerically validated that the effect of vertical component will be more concentrated in the upper stories rather the lower ones. Furthermore, the base shear ratio estimated for linear to nonlinear analysis scheme was obtained in between 0.34 and 1.89 [86]. Yamazaki et al. [87] also studied the effects of vertical excitations on steel frame constructions. They concluded that the fluctuation of axial force in weak columns is more significant than the same in weak beams. The numerical and experimental analyses highlighted that the ratio of vertical to horizontal fundamental vibration period was 0.2 or less [87]. Their analysis also highlighted that the vertical excitation would affect the interstory drift in the range of $\pm 3 \%$, which indicates that the horizontal excitation dominates the lateral displacement significantly than the vertical one. The authors concluded that the increase in axial force will give rise to significant reduction in shear capacity and thus aggravate the possibility of shear failure. Guo et al. [88] studied the combined effect of horizontal and vertical ground shaking on RC chimneys using fragility based assessment. They considered near-field ground motions to assess the seismic behavior and constructed fragility functions. They concluded that the likelihood of failure will be significantly increased when horizontal component of ground shaking intensity is significantly large. They recommend the use of combined horizontal and vertical excitations in seismic vulnerability assessment of RC chimneys. Similarly, Nezamabadi et al. [89] assessed performance of regular and mass asymmetric structures. They outlined that the near-fault vertical shaking will have significance, and thus the vertical design spectrum can be used to incorporate the effects arising from strong vertical shaking in near-fault regions. Furukawa et al. [90] conducted full scale shake table testing to assess the seismic response of base-isolated structure considering vertical excitation. The analysis performed by [91] showed that the displacements will be increased by up to $56 \%$ in a three-storied steel building when considering the vertical component of ground shaking. However, they used near-fault strike-normal strong ground motions only. They also noted that the vertical shaking will increase axial forces in column.

Several other studies perform analysis of building systems with base isolation to quantify the effects of vertical excitation (e.g., [49, 74, 92-95], among others). From the above discussions and broad literature review, it should be noted that the necessity of consideration of vertical excitation in design and code formulation is a must to capture the anomalous behavior of buildings during earthquakes. Furthermore, it is clear that the strong vertical shaking in the global context is confined to the near-field regions only. As limited studies have duly focused on the impacts of vertical shaking and have reiterated the need for formulation of 
TABLE 1: Summary of strong motion records after some Himalayan earthquakes (modified from [113-115]).

\begin{tabular}{|c|c|c|c|c|c|c|}
\hline \multirow{2}{*}{ Accelerometric station } & \multirow{2}{*}{ Earthquake } & \multirow{2}{*}{ Epicentral distance $(\mathrm{km})$} & \multicolumn{3}{|c|}{ Recorded PGA (g) } & \multirow{2}{*}{$\mathrm{V} / \mathrm{H}$} \\
\hline & & & EW & NS & UD & \\
\hline NSC & Gorkha (2015) & 80 & 0.13 & 0.18 & 0.2 & 1.27 \\
\hline Kantipath & Gorkha (2015) & 81 & 0.13 & 0.14 & 0.17 & 1.26 \\
\hline Kirtipur & Gorkha (2015) & 80 & 0.25 & 0.15 & 0.12 & 0.58 \\
\hline Tribhuvan University & Gorkha (2015) & 81 & 0.22 & 0.16 & 0.14 & 0.73 \\
\hline Patan & Gorkha (2015) & 83 & 0.13 & 0.15 & 0.13 & 0.93 \\
\hline Thimi & Gorkha (2015) & 87 & 0.12 & 0.15 & 0.18 & 1.33 \\
\hline NSC & Nepal-Sikkim border (2011) & 272 & 0.032 & 0.05 & 0.018 & 0.43 \\
\hline Gangtok & Nepal-Sikkim border (2011) & 70 & 0.15 & 0.16 & 0.13 & 0.84 \\
\hline Siliguri & Nepal-Sikkim border (2011) & 115 & 0.16 & 0.2 & 0.12 & 0.66 \\
\hline
\end{tabular}

vertical spectra for analysis, no significant improvements could be found in the existing literature regarding this regard. Although the scope of the paper is limited to building structures only, the authors recognize the notable contributions in the field of bridge engineering considering the effects of vertical excitation as reported elsewhere (see, e.g., [66, 96-101], among others). Despite buildings and bridges, many researchers have considered the vertical excitation to assess the seismic performance of various types of structures (e.g., [88, 102-106], among others).

\section{Evidence and Avenues beyond Near-Field Regions}

Virtually all existing literatures report the strong vertical shaking during an earthquake in the near-field region only. On the contrary, the focus of this paper is to drag the attention of the researchers towards strong vertical shaking in the far-field region. Studies by Collier and Elnashai [62], Ambraseys and Simpson [11], Ambraseys and Douglas [107], Kalkan and Gulkan [108], Gulerce and Abrahamson [63], and Boomer et al. [109] highlighted that the vertical to horizontal spectral ratio is the function of source to site distance as well as local soil condition. Accordingly, the Kathmandu Valley as well as other valleys that are located in the alluvial deposit may observe significant local site effects during earthquakes (see, e.g., [43]). In this case, vertical excitation would be dominant and may result in anomalous damage mechanisms. The first evidence of strong vertical shaking and associated damage in Nepal was reported by Rana in 1935 [110]. In the monograph, the author reported that despite being $\sim 150 \mathrm{~km}$ away from the epicenter of the 1934 earthquake [111], buildings in Kathmandu Valley observed damage to the upper stories and also noted that the shaking was up down due to strong vertical shaking. Ground motion records in Nepal are available for 2011 and 2015 earthquakes only, so the account by Rana [110] cannot be numerically justified. Table 1 summarizes the peaks of horizontal and vertical components of recorded earthquakes in central Himalaya together with the epicentral distances and $\mathrm{V} / \mathrm{H}$ ratios. As shown in Table 1, the 2011 earthquake was recorded at 70,115 , and $272 \mathrm{~km}$ from the epicenter. Notably, even the recording at $70 \mathrm{~km}$ shows $\mathrm{V} / \mathrm{H}$ ratio as 0.84 . Similarly, at $115 \mathrm{~km}$, the ratio appears to be 0.66 , and at $272 \mathrm{~km}$ from the epicenter (at Kathmandu), the ratio is still
0.43. Although significant damage did not occur in the instrumented location in Kathmandu Valley during the 2011 Sikkim-Nepal border earthquake, however, clear evidence of strong vertical shaking in the far-field was present. In 2015, Nepal was struck by a strong earthquake of moment magnitude 7.8. Several instrumental recordings are also available for the earthquake. As shown in Table 1, all except one recording in Kathmandu valley, which is more than $75 \mathrm{~km}$ far from the epicenter, depicted the $\mathrm{V} / \mathrm{H}$ ratio more than $2 / 3$ (Figure 2). At $80 \mathrm{~km}$ epicentral distance, the ratio is obtained as 1.33 . The range of $\mathrm{V} / \mathrm{H}$ in Kathmandu Valley is obtained between 0.58 and 1.33 . This signifies that the central Himalayan earthquakes are likely to depict strong if not strongest vertical shaking even in the far-field regions. Figure 3 depicts that the frequency of vertical shaking was $\sim 10 \mathrm{~Hz}$ which should have played a vital role in anomalous building damage as reported by Gautam et al. [111]. The accelerometric station is located on loose soil deposit area so there is also a possibility of seismic site effects. The Kathmandu basin is $\sim 500 \mathrm{~m}$ deep, and interbedding of silts, sands, and clay is dominant [112]. This could be one of the possible reasons behind the strongest vertical shaking in central Kathmandu during the 1934 and 2015 earthquakes.

As opposed to the world earthquakes, as reported by Broderick et al. [33] and Elnashai et al. [116], the central Himalayan earthquakes depict relatively similar or greater $\mathrm{V} / \mathrm{H}$ ratio even in the far-field regions when compared with the near-field records of Northridge and Kobe earthquakes. Apart from seismological evidence, the 2015 Gorkha earthquake in Nepal displayed exemplary evidence regarding the effects of strong vertical excitation in far-field. Figure 4 shows a soft-story building with a collapsed third story due to strong vertical shaking which is similar to the evidence presented by other researchers in the near-field regions. The excessive axial force due to vertical excitation that usually becomes more significant in upper stories should have caused the collapse. Except for the collapsed story, the building sustained minimal damage. Several cases of upper story collapse were reported in Kathmandu Valley, especially in the soft soil deposit locations. The $\mathrm{V} / \mathrm{H}$ ratio also depicts the higher value especially in the case of soft soil locations such as Thimi and NSC (Table 1). Similarly, shear damage in the columns in the seventh story of a 14-storied apartment building was prevalent in the downtown of Kathmandu. It is pertinent to note that shear damage to 


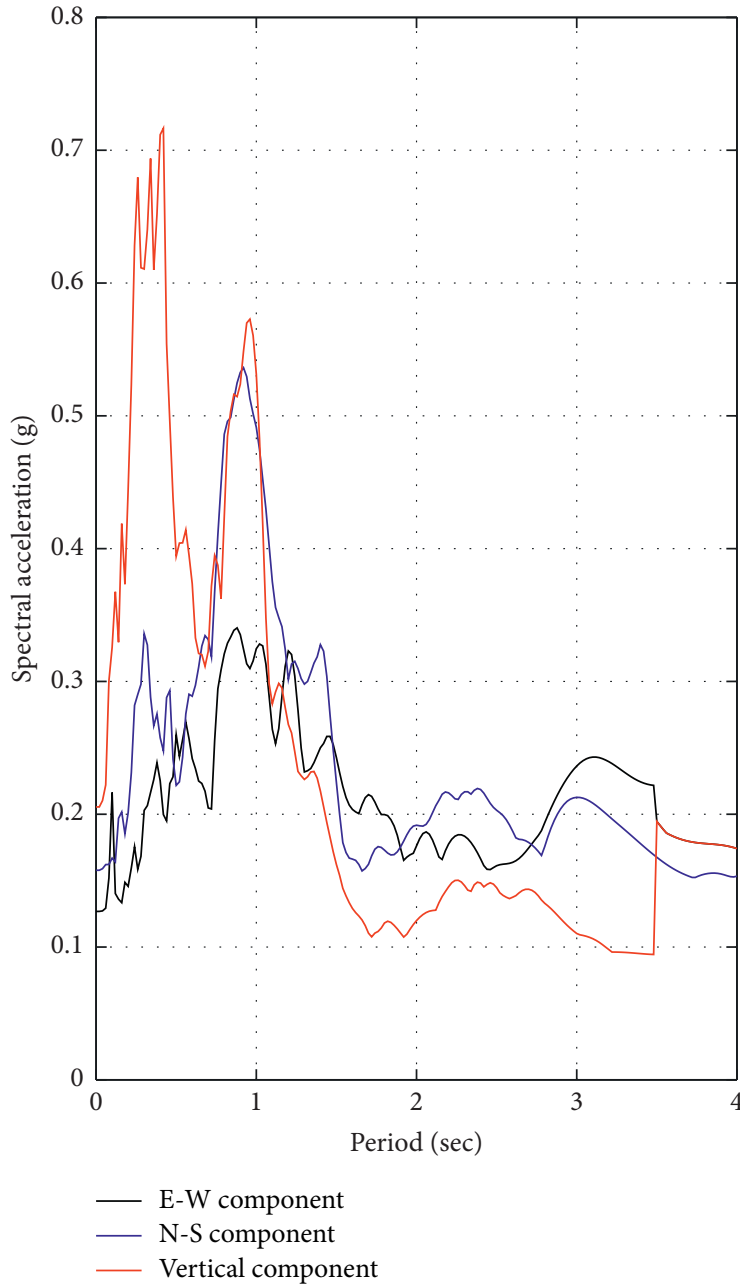

(a)

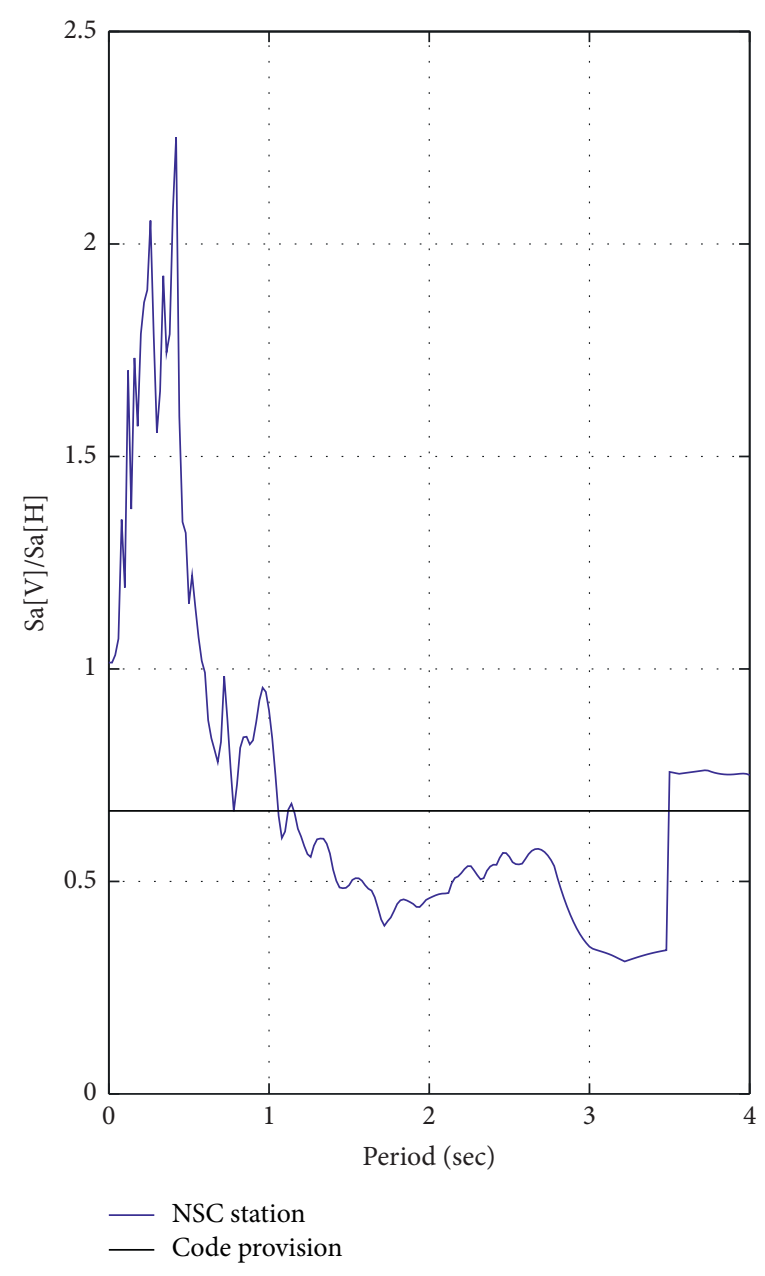

(b)

Figure 2: (a) Acceleration response spectra of the 2015 Gorkha earthquake recorded by National Seismological Center (NSC) [117] and (b) vertical to horizontal spectral ratio for the Gorkha earthquake.

columns in the location where maximum shear force is not expected (Figure 5), intermediate/upper story collapse (Figure 6), and shear-compression failure of internal columns among others clearly indicate the presence of strong vertical excitation during the Gorkha earthquake in the far-field regions. These shreds of evidence strongly demand due consideration of vertical excitation during seismic code formulation. The Nepal Building Code [31], on the contrary, does not account for the effects of the vertical shaking on building except for secondary structural elements. However, the earthquakes that struck Nepal Himalaya have consistently notified that the strong vertical shaking in far-field is significant. So, further research is needed to quantify the effects of strong far-field shaking beyond the conventional near-field analyses. To quantify the effects of strong far-field excitation, numerical studies and parametric analyses are required. We aim to perform studies based on finite element analysis considering strong far-field excitations considering parametric analyses. Furthermore, the effect of soil- structure interaction in the case of far-field vertical excitation will be more influential in terms of foundation performance. So, studies that consider the effect of soilstructure interaction together with strong far-field vertical shaking are also important to capture the anomalous behaviors of buildings that were observed during several historical earthquakes. In the case of strong far-field excitation, the conventional design guidelines may not assure adequate seismic performance as shear damage in the middle portion of columns, higher axial force demand in the upper story column, and others could lead to unprecedented mechanisms and damages. Thus, experimental campaigns considering the effects of strong farfield vertical excitations will further advance the understanding regarding the mechanisms and possible remedial measures that could be implemented in building codes. To achieve the target performance of buildings in seismic areas, the occurrence and possible effects of strong farfield shaking should also be considered in contemporary seismic designs and assessments. 


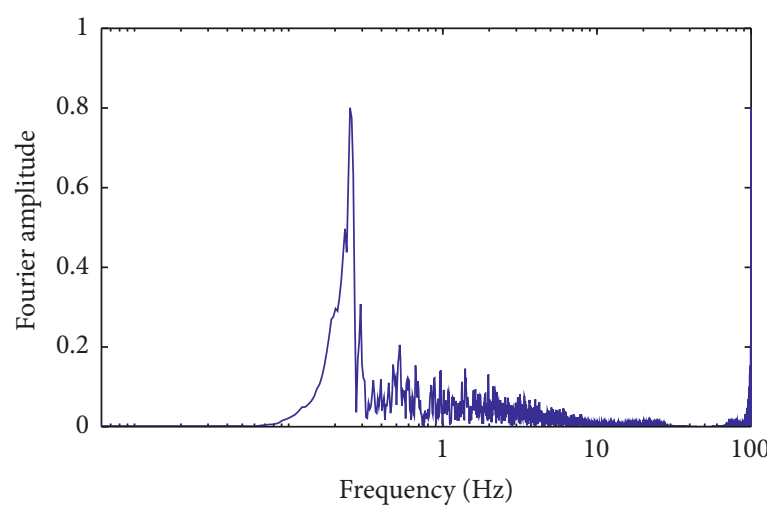

$-\mathrm{E}-\mathrm{W}$

(a)

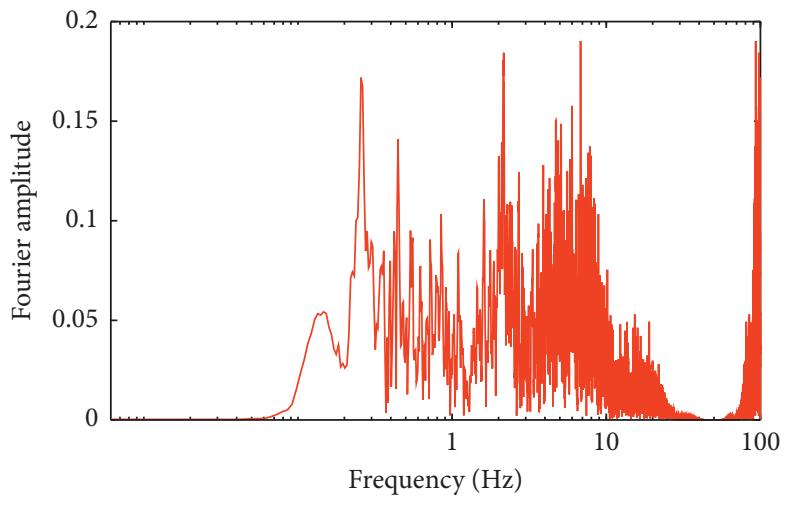

U-D

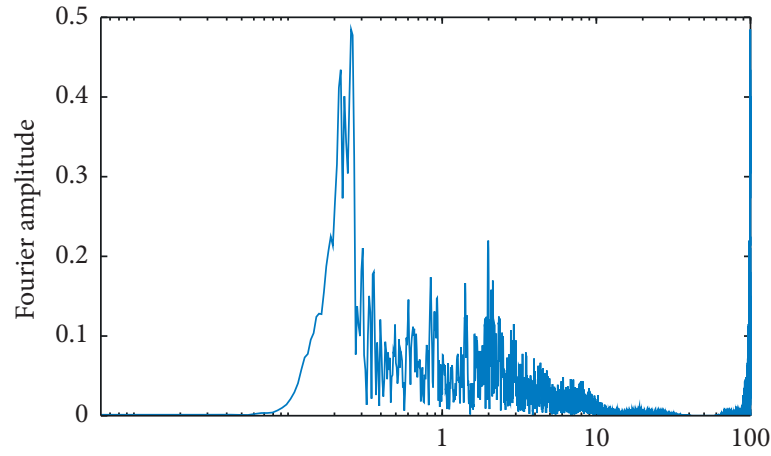

Frequency $(\mathrm{Hz})$

(b)

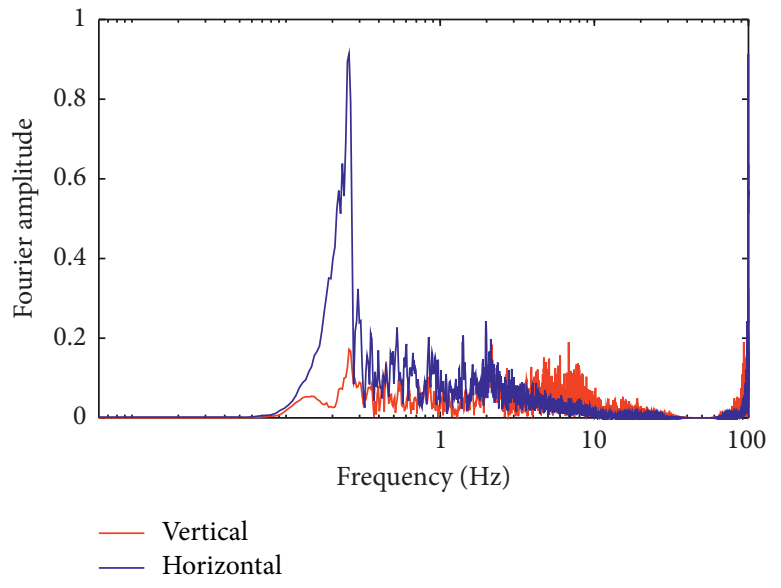

(d)

FIGURE 3: Fourier spectra of the Gorkha earthquake: (a) east-west (E-W) component, (b) north-south (N-S) component, (c) vertical (U-D) component, and (d) vertical and horizontal components.

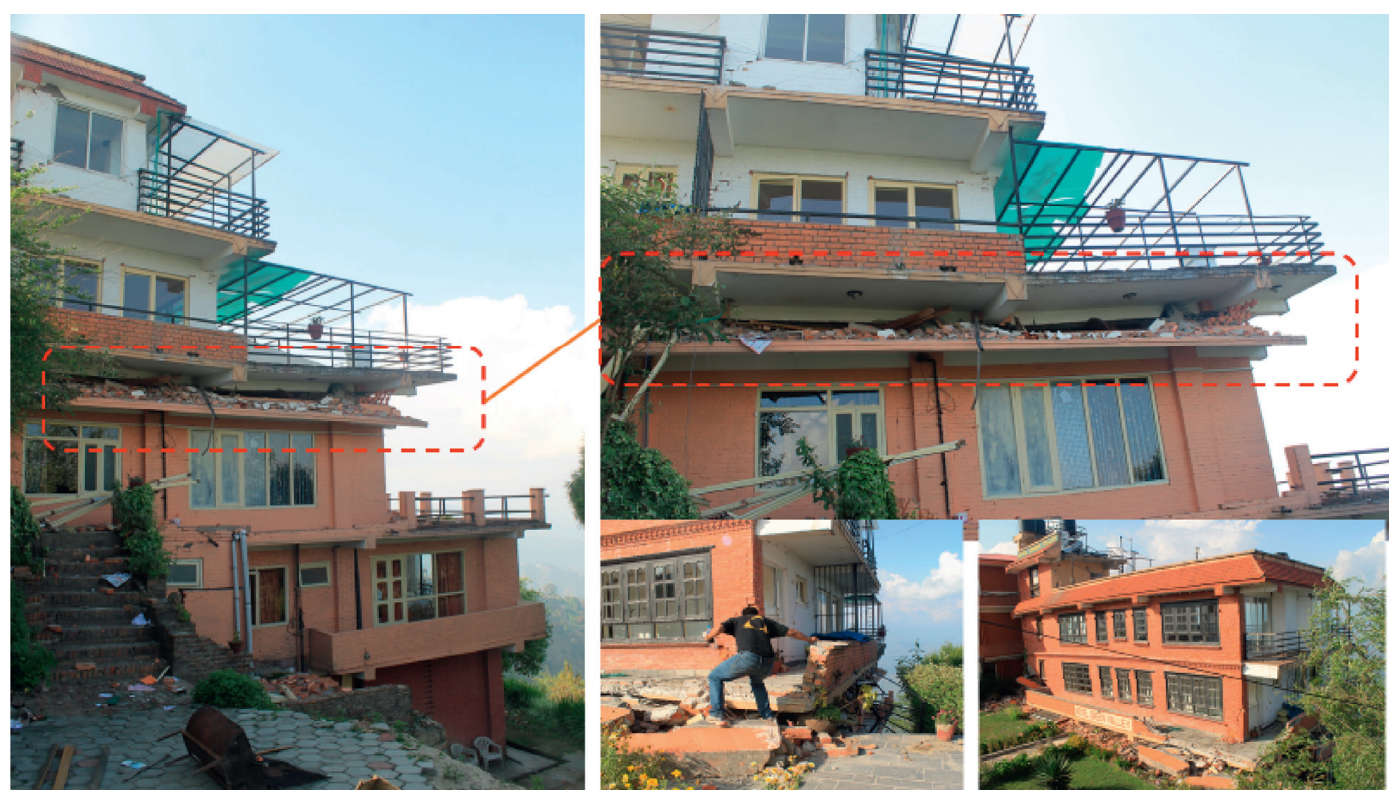

Figure 4: Intermediate story collapse in a modern hotel building compliant to the prevalent code at Nagarkot, Bhaktapur, Nepal. 


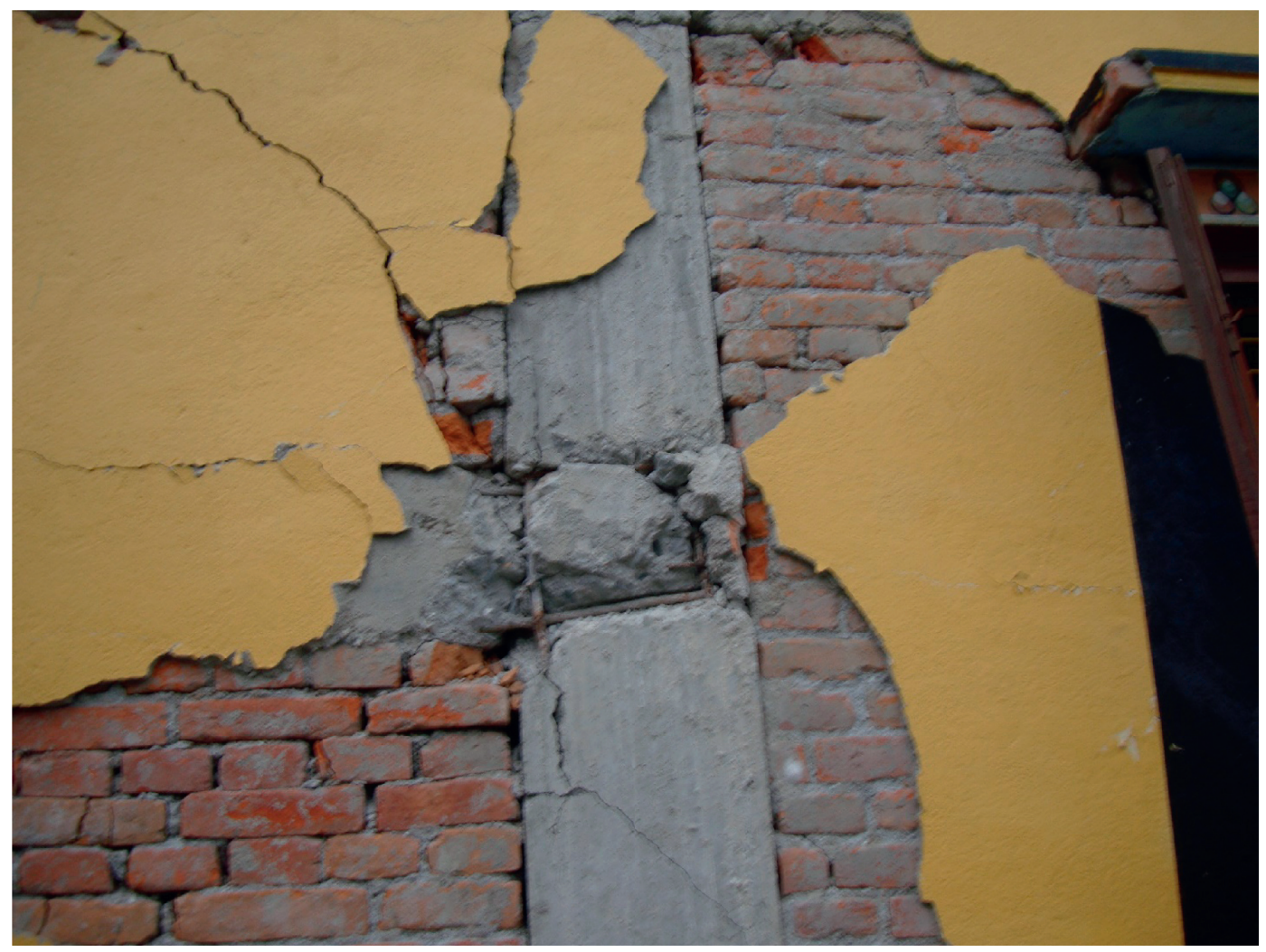

FIgURE 5: Shear damage of a column at midheight in Kathmandu due to the 2015 Gorkha earthquake.

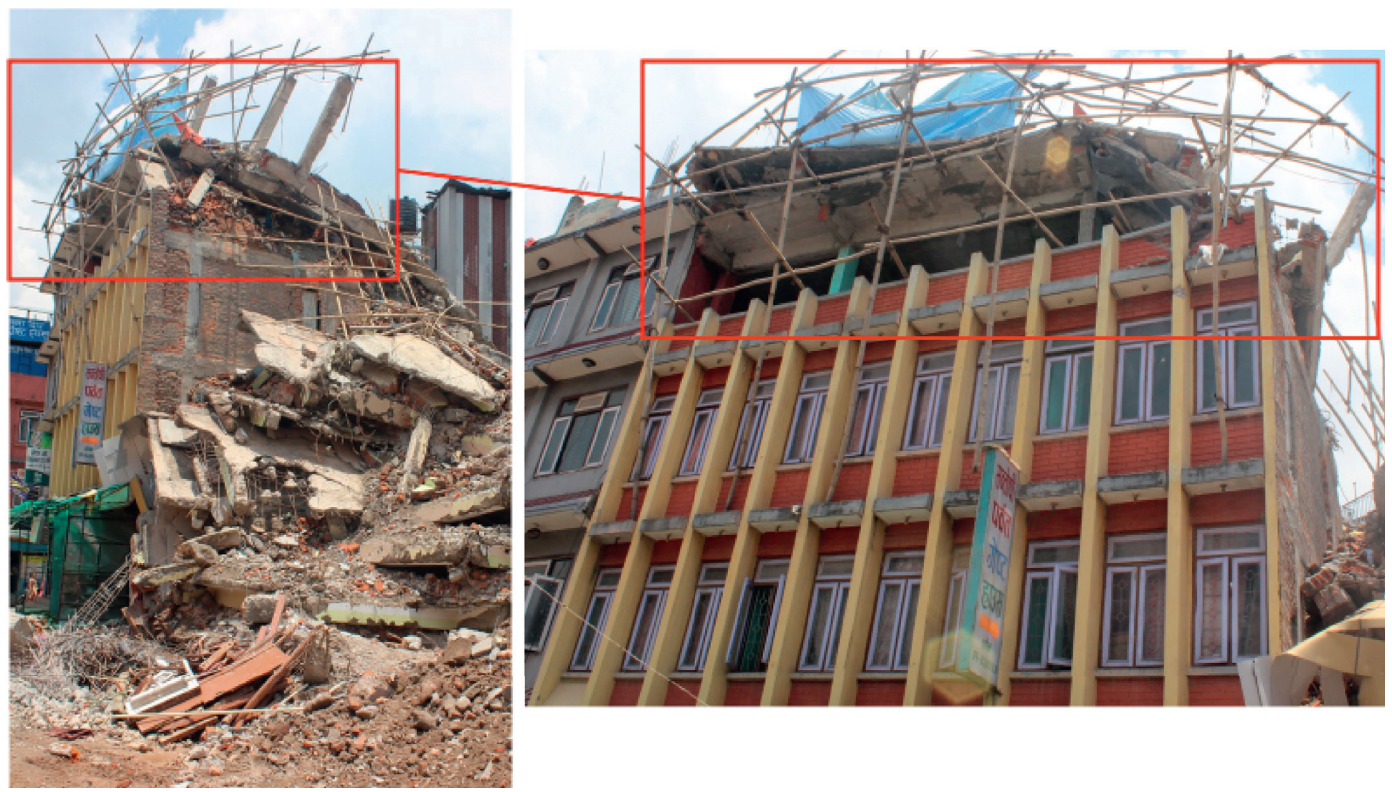

FIGURE 6: Collapsed top story in a soft-story building in Kathmandu by the Gorkha earthquake.

\section{Conclusion}

A systematic review on the effect of vertical shaking on buildings is presented in this study. With the help of a broad literature review, the evidence for near-field and far-field vertical excitations is summarized. The sum of the reported evidence highlights that there are anomalous damage mechanisms that could not be explained by the conventional analyses. This supports the significance of inclusion of strong vertical excitation in the far-field regions too. Numerical simulation results presented by several researchers also highlight the clear evidence of detrimental impacts on 
structures at least in terms of greater axial forces in the upper stories, occurrence of shear damage in noncritical regions, damage to interior columns, and variation in base shear, among others. However, virtually all previous works focused on the near-field regions only; thus, the strong far-field vertical excitation has not gotten adequate attention so far. The evidence from central Himalayan earthquakes shows that the strong/strongest vertical shaking is not limited to the near-field regions only and that may also lead to detrimental impacts on structures in the far-field regions. The damage mechanisms in far-field regions due to recent earthquakes are presented together with the $\mathrm{V} / \mathrm{H}$ ratios of accelerometric records. It is concluded that there is a dire need for investigation regarding the occurrence of strong vertical shaking in the far-field regions as well and its impacts on structures and infrastructures. Further numerical and experimental campaigns are required to address this scenario. In addition, seismic codes should also consider the impacts of strong far-field vertical excitations. This study reports only a few pieces of evidence of occurrence of strong vertical excitation in the far-field regions and the related damages. The authors would perform numerical analysis using strong far-field vertical excitation to assess the seismic performance of RC buildings. Moreover, future works may also consider experimental studies implementing strong far-field vertical excitations.

\section{Data Availability}

The data used to support the findings of this study are included within the article.

\section{Conflicts of Interest}

The authors declare that they have no conflicts of interest.

\section{References}

[1] Z. P. Wen, Y. X. Hu, and K. T. Chau, "Site effect on vulnerability of high-rise shear wall buildings under near and far field earthquakes," Soil Dynamics and Earthquake Engineering, vol. 22, pp. 1175-1182, 2002.

[2] A. Aziminejad and A. S. Moghadam, "Fragility-based performance evaluation of asymmetric single-story buildings in near field and far field earthquakes," Journal of Earthquake Engineering, vol. 14, pp. 789-816, 2010.

[3] C. Jäger and C. Adam, "Influence of collapse definition and near-field effects on collapse capacity spectra," Journal of Earthquake Engineering, vol. 17, pp. 859-878, 2013.

[4] E. N. Farsangi, A. A. Tasnimi, and B. Mansouri, "Fragility assessment of RC-MRFs under concurrent vertical-horizontal seismic action effects," Computers and Concrete, vol. 16, no. 1, pp. 99-123, 2015.

[5] Y. Yazdani and M. Alembagheri, "Seismic vulnerability of gravity dams in near-fault areas," Soil Dynamics and Earthquake Engineering, vol. 102, 2017.

[6] F. S. Akhavan Hejazi and M. Khan Mohammadi, "Investigation on sloshing response of water rectangular tanks under horizontal and vertical near fault seismic excitations," Soil Dynamics and Earthquake Engineering, vol. 116, pp. 673653, 2019.
[7] N. M. Newmark, J. A. Blume, and K. K. Kapur, "Seismic design spectra for nuclear power plants," Journal of the Power Division, vol. 99, no. 2, pp. 287-303, 1973.

[8] A. Elgamal and L. He, "Vertical earthquake ground motion records: an overview," Journal of Earthquake Engineering, vol. 8, pp. 663-697, 2004.

[9] Y. Bozorgnia and M. Niazi, "Distance scaling of vertical and horizontal response spectra of the Loma Prieta earthquake," Earthquake Engineering and Structural Dynamics, vol. 22, pp. 695-707, 1993.

[10] M. Niazi and Y. Bozorgnia, "Behaviour of near-source vertical and horizontal response spectra at smart-1 array, Taiwan," Earthquake Engineering and Structural Dynamics, vol. 21, pp. 37-50, 1992.

[11] N. N. Ambraseys and K. A. Simpson, "Prediction of vertical response spectra in Europe," Earthquake Engineering and Structural Dynamics, vol. 25, pp. 401-412, 1996.

[12] T. Furumura, "Destructive near-fault strong ground motion from the 2016 kumamoto prefecture, japan, m7.3 earthquake," Landslides, vol. 13, 2016.

[13] A. Rosti, M. Rota, and A. Penna, "Damage classification and derivation of damage probability matrices from L'Aquila (2009) post-earthquake survey data," Bulletin of Earthquake Engineering, vol. 16, 2018.

[14] A. Scala, G. Festa, and S. Del Gaudio, "Relation between near-fault ground motion impulsive signals and source parameters," Journal of Geophysical Research: Solid Earth, vol. 123, pp. 7707-7721, 2018.

[15] A. Akinci, L. Malagnini, and F. Sabetta, "Characteristics of the strong ground motions from the 6 April 2009 L'Aquila earthquake, Italy," Soil Dynamics and Earthquake Engineering, vol. 30, pp. 320-335, 2010.

[16] S. Ruiz, "Short-period rupture process of the $2010 \mathrm{mw} 8.8$ maule earthquake in Chile," Earthquake Spectra, 2012.

[17] K. S. Khan, R. Kunz, J. Kleijnen, and G. Antes, "Five steps to conducting a systematic review," Journal of the Royal Society of Medicine, vol. 96, no. 3, pp. 118-121, 2003.

[18] A. J. Papazoglou and A. S. Elnashai, "Analytical and field evidence of the damaging effect of vertical earthquake ground motion," Earthquake Engineering and Structural Dynamics, vol. 25, pp. 1109-1137, 1996.

[19] S. A. Anagnostopolous, D. Rinaldis, V. A. Lekidis, V. N. Margaris, and N. P. Theodulidis, "The Kalamata, Greece, earthquake of September 13, 1986," Earthquake Spectra, 1987.

[20] A. S. Elnashai and K. Pilakoutas, The Kalamata (Greece) Earthquake of 13 September 1986, London, 1986.

[21] A. J. Papazoglou, Near-source Vertical Earthquake Ground Motion; an Assessment of Causes and Effects, Imperial College, London, 1995.

[22] A. S. Elnashai and A. J. Papazoglou, Vertical Earthquake Ground Motion; Evidence, Effects and Simplified Analysis Procedures, 1995.

[23] A. S. Elnashai, K. Pilakoutas, and N. N. Ambraseys, "The Kalamata earthquake: performance of reinforced concrete buildings," in SECED con\$ on Ciuil Engineering Dynamics, pp. 193-207, 1988.

[24] A. S. Elnashai, K. Pilakoutas, N. N. Ambraseys, and I. D. Lefas, "Lessons learnt from the Kalamata (Greece) earthquake of 13 september 1986," European Journal of Environment and Earth Sciences, vol. 1, pp. 11-19, 1987.

[25] G. M. Verderame, F. De Luca, P. Ricci, and G. Manfredi, "Preliminary analysis of a soft-storey mechanism after the 
2009 L'Aquila earthquake," Earthquake Engineering and Structural Dynamics, vol. 40, pp. 925-944, 2011.

[26] H. Alinouri, F. A. Danesh, and S. B. Beheshti-Aval, "Effect of soft-storey mechanism caused by infill elimination on displacement demand in nonlinear static procedure using coefficient method," Structural Design of Tall and Special Buildings, vol. 22, pp. 1296-1309, 2013.

[27] M. Georgantzis, Effect of Vertical Motion on Behaviour Factors, Imperial College, London, 1995.

[28] O. Papadopoulou, The Effect of Vertical Excitation on Reinforced Concrete Multi-Storey Structures, Imperial College, London, 1989.

[29] C. Papaleontiou and J. M. Roesset, "Effect of vertical accelerations on seismic response of frames," in Structural Dynamics EURODYNvol. 93, pp. 19-26, 1993.

[30] M. Fardis, Analysis and Design of Reinforced Concrete Buildings According to EC-2 and EC-8, 1994.

[31] Government of Nepal, Nepal National Building Code, Government of Nepal, Nepal, 1994.

[32] Bureau of Indian Standards, Indian Standard IS. IS 1893 (Part 1): 2002: Criteria for Earthquake Resistant Design of Structures, Bureau of Indian Standards, India, 5th revision, 2002.

[33] B. M. Broderick, A. S. Elnashai, N. N. Ambraseys, J. J. Barr, R. G. Goodfellow, and E. M. Higazy, The Northridge (California) Earthquake of 17 January 1994: Observations, StrongMotion and Correlative Response Analyses, London, 1994.

[34] A. S. Elnashai and A. J. Papazoglou, "Procedure and spectra for analysis of rc structures subjected to strong vertical earthquake loads," Journal of Earthquake Engineering, vol. 1, pp. 121-155, 1997.

[35] A. Ghobarah and A. S. Elnashai, "Contribution of vertical ground motion to the damage of RC building," in Proceedings of the 11th European Conference on Earthqiake Engineering, Paris, France, September 1998.

[36] P. P. Diotallevi and L. Landi, "Effect OF the axial force and OF the vertical ground motion component ON the seismic response OF R/C frames," ", in Proceedings of the 12th World Conference in Earthquake Engineering, p. 1026, Auckland, New Zealand, February 2000.

[37] T. Perea and L. Esteva, "Analysis of vertical ground motions of near source records in Mexico," in Proceedings of the 13th World Conference on Earthquake Engineering, p. 1852, Vancouver, BC, Canada, August 2004.

[38] A. S. Elnashai, L. He, and A. Elgamal, "Spectra for vertical earthquake ground motion," in Proceedings of the 13th World Conference on Earthquake Engineering, p. 2309, Vancouver, BC, Canada, August 2004.

[39] Y. Bozorgnia, K. W. Campbell, and M. Niazi, "Observed spectral characteristics OF vertical ground motion recorded during worldwide earthquakes from 1957 to 1995," in Proceedings of the 12th World Conference in Earthquake Engineering, p. 2671, Auckland, New Zealand, February 2000.

[40] I. A. Beresnev, A. M. Nightengale, and W. J. Silva, "Properties of vertical ground motions," Bulletin of the Seismological Society of America, vol. 92, no. 8, pp. 3152-3164, 2002.

[41] C. H. Loh and M. J. Ma, "Reliability assessment of structure subjected to horizontal-vertical random earthquake excitations," Structural Safety, vol. 19, no. 1, 1997.

[42] B. Fry, "Strong shaking in recent New Zealand earthquakes," Eos (Washington. DC), vol. 92, no. 41, pp. 349-351, 2011.

[43] R. Rupakhety, S. Olafsson, and B. Halldorsson, "The 2015 Mw 7.8 Gorkha Earthquake in Nepal and its aftershocks: analysis of strong ground motion," Bulletin of Earthquake Engineering, vol. 15, 2017.

[44] R. Rupakhety, "Seismotectonic and Engineering Seismological Aspects of the M W 7.8 Gorkha, Nepal, Earthquake," in Impacts and Insights of Gorkha Earthquake in Nepal, pp. 19-45, Elsevier, 2018.

[45] F. Mazza and A. Vulcano, "Effects of the vertical acceleration on the response of base-isolated structures subjected to nearfault ground motions," in Proceedings of the 13th World Conference on Earthquake Engineering, p. 2934, Vancouver, BC, Canada, August 2004.

[46] V. Loghman, F. Khoshnoudian, and M. Banazadeh, "Effect of vertical component of earthquake on seismic responses of triple concave friction pendulum base-isolated structures," JVC/Journal Vibration and Control, 2015.

[47] M. Dana, "Effects of the seismic vertical component on structural behavior - an analytical study of current code practices and potential areas of improvement," in Proceedings of the NCEE 2014 - 10th U.S. National Conference on Earthquake Engineering: Frontiers of Earthquake Engineering, Anchorage, AL, USA, July 2014.

[48] L. Di Sarno, A. S. Elnashai, and G. Manfredi, "Assessment of RC columns subjected to horizontal and vertical ground motions recorded during the 2009 L'Aquila (Italy) earthquake," Engineering Structures, vol. 33, pp. 1514-1535, 2011.

[49] F. Mazza and A. Vulcano, "Effects of near-fault ground motions on the nonlinear dynamic response of base-isolated r.c. framed buildings," Earthquake Engineering and Structural Dynamics, vol. 41, pp. 211-232, 2012.

[50] F. Mazza, "Nonlinear dynamic response of RC buildings with different base isolation systems subjected to horizontal and vertical components of near-fault ground motions," Open Construction and Building Technology Journal, vol. 12, pp. 135-144, 2012.

[51] G. Rinaldin, M. Fasan, S. Noé, and C. Amadio, "The influence of earthquake vertical component on the seismic response of masonry structures," Engineering Structure, vol. 185, pp. 184-193, 2019.

[52] D. Liberatore, C. Doglioni, O. AlShawa, S. Atzori, and L. Sorrentino, "Effects of coseismic ground vertical motion on masonry constructions damage during the 2016 Amatrice-Norcia (Central Italy) earthquakes," Soil Dynamics and Earthquake Engineering, vol. 120, pp. 423-435, 2019.

[53] L. Elhifnawy, H. Abou-Elfath, and E. El-Hout, "Inelastic performance of RC buildings subjected to near-source multicomponent earthquakes," Alexandria Engineering Journal, vol. 56, pp. 511-522, 2017.

[54] H. Abdollahiparsa, P. Homami, and F. Khoshnoudian, "Effect of vertical component of an earthquake on steel frames considering soil-structure interaction," KSCE Journal of Civil Engineering, vol. 20, 2016.

[55] B. Asgarian, A. Norouzi, P. Alanjari, and M. Mirtaheri, "Evaluation of seismic performance of moment resisting frames considering vertical component of ground motion," Advances in Structural Engineering, vol. 15, no. 8, pp. 1439-1453, 2012.

[56] S. J. Kim, C. J. Holub, and A. S. Elnashai, "Analytical assessment of the effect of vertical earthquake motion on RC bridge piers," Journal of Structural Engineering, vol. 137, 2011.

[57] Z. Wang, L. Dueñas-Osorio, and J. E. Padgett, "Seismic response of a bridge-soil-foundation system under the combined effect of vertical and horizontal ground motions," 
Earthquake Engineering and Structural Dynamics, vol. 42, pp. 545-564, 2013.

[58] N. Hosseinzadeh, "Vertical component effect OF earthquake IN seismic performance OF reinforced concrete bridge piers," in Proceedings of the 14th World Conference on Earthquake Engineering, Beijing, China, October 2008.

[59] H. Lee and K. M. Mosalam, "Seismic evaluation of the shear behavior in reinforced concrete bridge columns including effect of vertical accelerations," Earthquake Engineering and Structural Dynamics, vol. 43, pp. 317-337, 2014.

[60] J. C. Anderson and V. V. Bertero, "Uncertainties in establishing design earthquakes," Journal of Structural Engineering (United States), vol. 113, 1987.

[61] S. H. Ju, C. W. Liu, and K. Z. Wu, "3D analyses of buildings under vertical component of earthquakes," Journal of Structural Engineering, vol. 126, 2000.

[62] C. J. Collier and A. S. Elnashai, "A procedure for combining vertical and horizontal seismic action effects," Journal of Earthquake Engineering, vol. 5, pp. 521-539, 2001.

[63] Z. Gülerce and N. A. Abrahamson, "Site-specific design spectra for vertical ground motion," Earthquake Spectra, 2011.

[64] Z. Gulerce, E. Erduran, S. K. Kunnath, and N. A. Abrahamson, "Seismic demand models for probabilistic risk analysis of near fault vertical ground motion effects on ordinary highway bridges," Earthquake Engineering and Structural Dynamics, Article ID 1123, 2012.

[65] G. P. Warn and A. S. Whittaker, "Vertical earthquake loads on seismic isolation systems in bridges," Journal of Structural Engineering, vol. 134, 2008.

[66] B. Wei, C. Zuo, X. He, L. Jiang, and T. Wang, "Effects of vertical ground motions on seismic vulnerabilities of a continuous track-bridge system of high-speed railway," Soil Dynamics and Earthquake Engineering, 2018.

[67] N. Augenti and F. Parisi, "'Learning from construction failures due to the 2009 L'Aquila, Italy, earthquake," Journal of Performance of Constructed Facilities, vol. 24, 2010.

[68] D. Gautam and H. Chaulagain, "Structural performance and associated lessons to be learned from world earthquakes in Nepal after 25 April 2015 ( $\mathrm{M}_{\mathrm{W}}$ 7.8) Gorkha earthquake," Engineering Failure Analysis, vol. 68, 2016.

[69] S. J. Kim and A. S. Elnashai, "Characterization of shaking intensity distribution and seismic assessment of RC buildings for the Kashmir (Pakistan) earthquake of October 2005," Engineering Structure, vol. 31, no. 12, 2009.

[70] M. Bovo, A. Barbaresi, D. Torreggiani, and P. Tassinari, "Collapse and damage to vernacular buildings induced by 2012 Emilia earthquakes," Bulletin of Earthquake Engineering, vol. 18, no. 3, 2020.

[71] F. Nadim, "The bam earthquake of 26 december 2003," Bulletin of Earthquake Engineering, vol. 2, no. 2, 2004.

[72] Ö. Kale and S. Akkar, "A new formulation for a code-based vertical design spectrum," Earthquake Engineering and Structural Dynamics, vol. 49, pp. 936-980, 2020.

[73] M. Ercolino, G. Magliulo, and G. Manfredi, "Failure of a precast RC building due to Emilia-Romagna earthquakes," Engineering Structure, vol. 118, 2016.

[74] H. Shakib and A. Fuladgar, "Response of pure-friction sliding structures to three components of earthquake excitation," Computers and Structures, vol. 81, no. 4, 2003.

[75] T. C. Liauw, Q. L. Tian, and Y. K. Cheung, "Structures on sliding base subject to horizontal and vertical motions," Journal of Structural Engineering, vol. 114, no. 9, 1988.
[76] B. C. Lin and I. Tadjbakhsh, "“Effect of vertical motion on friction-driven isolation systems," Earthquake Engineering and Structural Dynamics, vol. 14, no. 4, 1986.

[77] E. Lim, L. Jiang, and N. Chouw, "Dynamic response of a non-structural component with three supports in multi-directional earthquakes," Engineering Structure, vol. 150, 2017.

[78] Y. Xiang, Y. Feng Luo, Z. Chen Zhu, and Z. Yan Shen, "Estimating the response of steel structures subjected to vertical seismic excitation: idealized model and inelastic displacement ratio," Engineering Structure, vol. 148, 2017.

[79] Y. Xiang and Q. L. Huang, "Damping modification factor for the vertical seismic response spectrum: a study based on Japanese earthquake records," Engineering Structure, vol. 179, 2019.

[80] J. Náprstek and C. Fischer, "Dynamic stability of a vertically excited non-linear continuous system," Computers and Structures, vol. 155, 2015.

[81] K. Ren, "Assessing the reliability, resilience and vulnerability of water supply system under multiple uncertain sources," Journal of Cleaner Production, vol. 252, Article ID 119806, 2020.

[82] V. V. Bertero, S. A. Mahin, and R. A. Herrera, "Aseismic design implications of near-fault san fernando earthquake records," Earthquake Engineering and Structural Dynamics, vol. 6, no. 1, 1978 .

[83] Y. Tian, X. Liu, and S. George, "Effects of vertical ground motion on seismic performance of reinforced concrete flatplate buildings," Journal of Structural Engineering, vol. 146, no. 12, 2020.

[84] S. Kim, S. J. Kim, and C. Chang, "Analytical assessment of the effect of vertical ground motion on RC frames designed for gravity loads with various geometric configurations," $\mathrm{Ad}$ vances in Civil Engineering, vol. 2018, Article ID 4029142, 11 pages, 2018.

[85] Y. Lu, G. Mosqueda, Q. Han, and Y. Zhao, "Shaking table tests examining seismic response of suspended ceilings attached to large-span spatial structures," Journal of Structural Engineering, vol. 144, no. 9, 2018.

[86] M. Hosseini and M. F. Nezamabadi, "A study on the effect of vertical ground on the seismic response of steel buildigns," in Proceedings of the 13th World Conference on Earthquake Engineering, vol. 1368, pp. 3-8, Vancouver, BC, Canada, August 2004.

[87] S. Yamazaki, S. Minami, H. Mimura, and K. Udagawa, "Effects of vertical ground motions on earthquake response of of steel frames," in Proceedings of the 12th World Conference on Earthquake Engineering, p. 0663, Auckland, New Zealand, 2000.

[88] X. Guo, W. Chen, and J. Yu, "Combined effect of vertical and horizontal ground motions on failure probability of RC chimneys," Advances in Civil Engineering, vol. 2018, Article ID 9327403, 11 pages, 2018.

[89] M. F. Nezamabadi and F. Y. Vayeghan, "Development of seismic criteria for seismic responses of regular and irregular structures in plan considering vertical component of the nearfield records," Journal of Structural Engineering, vol. 5, no. 1, pp. 9-20, 2015.

[90] S. Furukawa, E. Sato, Y. Shi, T. Becker, and M. Nakashima, "Full-scale shaking table test of a base-isolated medical facility subjected to vertical motions," Earthquake Engineering and Structural Dynamics, vol. 42, no. 13, 2013.

[91] G. MacRae, D. Fields, I. Turkman, and H. Tagawa, "Effect of shaking characteristics on steel moment-resisting frames," Structural Congress 2000, vol. 103, pp. 1-8, 2004. 
[92] W. Eltahawy and K. L. Ryan, "Performance of flexible frame building with horizontal and 3D seismic isolation when subjected to 3D ground shaking," Earthquake Spectra, vol. 36, no. 4, 2020.

[93] B. L. Khan, M. Azeem, M. Usman, S. H. Farooq, A. Hanif, and M. Fawad, "Effect of near and far field earthquakes on performance of various base isolation systems," In Procedia Structural Integrity, vol. 18, 2019.

[94] D. Liu, Y. Liu, D. Sheng, and W. Liao, "Seismic response analysis of an isolated structure with QZS under near-fault vertical earthquakes," Shock Vibration, vol. 2018, Article ID 9149721, 12 pages, 2018.

[95] Y. N. Huang, A. S. Whittaker, R. P. Kennedy, and R. L. Mayes, "Response of base-isolated nuclear structures for design and beyond-design basis earthquake shaking," Earthquake Engineering and Structural Dynamics, vol. 42, no. 3, 2013.

[96] S. H. Kim and M. Q. Feng, "Fragility analysis of bridges under ground motion with spatial variation," International Journal of Non-Linear Mechanics, vol. 38, pp. 705-721, 2003.

[97] K. H. Abdelkareem and A. MachidA, "No TitleEffect of vertical motion of earthquake on failure mode and ductility of RC bridge piers," in Proceedings of the 12th World Conference in Earthquake Engineering, Auckland, New Zealand, February 2000.

[98] M. Zahedi, G. Ghodrati Amiri, and M. Akbarzadeh, "Characteristics of vertical spectrum in near-field region and investigation of its effects on the dynamic response of bridges," in Proceedings of the 4th International Conference on Earthquake Geotechnical Engineering, p. 1535, Thessaloniki, Greece, June 2007.

[99] K. D. Makan, Y. Chen, T. Larkin, and N. Chouw, "The influence of vertical seismic ground motion on structures with uplift," in Proceedings of the 2013NZSEE Conference, Wellongton, New Zealand, 2013.

[100] S. K. Kunnath, E. Erduran, Y. H. Chai, and M. Yashinsky, "Effect of near-fault vertical ground motions on seismic response of highway overcrossings," Journal of Bridge Engineering, vol. 13, 2008.

[101] A. M. Abdel-Ghaffar and L. I. Rubin, "Vertical seismic behaviour of suspension bridges," Earthquake Engineering and Structural Dynamics, vol. 11, no. 1, 1983.

[102] S. Zhang and G. Wang, "Effects of near-fault and far-fault ground motions on nonlinear dynamic response and seismic damage of concrete gravity dams," Soil Dynamics and Earthquake Engineering, vol. 53, 2013.

[103] M. Breccolotti and A. L. Materazzi, "The role of the vertical acceleration component in the seismic response of masonry chimneys," Materials and Structures, vol. 49, no. 1-2, pp. 29-44, 2016.

[104] F. Faridafshin and G. McClure, "Seismic response of tall guyed masts to asynchronous multiple-support and vertical ground motions," Journal of Structural Engineering, vol. 134, no. 8, pp. 1374-1382, 2008.

[105] D. Konstantinidis and N. Makris, "Experimental and analytical studies on the response of freestanding laboratory equipment to earthquake shaking," Earthquake Engineering and Structural Dynamics, vol. 38, no. 6, 2009.

[106] A. M. Sweedan and A. A. El Damatty, "Equivalent models of pure conical tanks under vertical ground excitation," Journal of Structural Engineering, vol. 131, no. 5, 2005.

[107] N. N. Ambraseys and J. Douglas, "Near-field horizontal and vertical earthquake ground motions," Soil Dynamics and Earthquake Engineering, vol. 23, pp. 1-18, 2003.
[108] E. Kalkan and P. Gülkan, "Empirical attenuation equations for vertical ground motion in Turkey," Earthquake Spectra, 2004.

[109] J. J. Bommer, S. Akkar, and Ö. Kale, "A model for vertical-tohorizontal response spectral ratios for Europe and the middle east," Bulletin of the Seismological Society of America, vol. 101, pp. 1783-1806, 2011.

[110] B. Rana, The Great Earthquake of Nepal, I, Jorganesh Press, Kathmandu, Nepal, 1935.

[111] D. Gautam, G. Fabbrocino, and F. Santucci de Magistris, "Derive empirical fragility functions for Nepali residential buildings," Engineering Structure, 2018.

[112] D. Gautam, G. Fabbrocino, and F. Santucci de Magistris, "Derive empirical fragility functions for Nepali residential buildings," Engineering Structure, vol. 171, pp. 617-628, 2018.

[113] D. Gautam, F. S. de Magistris, and G. Fabbrocino, "Soil liquefaction in Kathmandu valley due to 25 April 2015 Gorkha, Nepal earthquake," Soil Dynamics and Earthquake Engineering, vol. 97, 2017.

[114] D. Gautam, "Seismic performance of world heritage sites in Kathmandu valley during Gorkha seismic sequence of aprilmay 2015," Journal of Performance of Constructed Facilities, vol. 31, no. 5, 2017.

[115] Earthquake Engineering Research Institute, The $M w 6.9$ Sikkim-Nepal Border Earthquake of September 18, 2011, Earthquake Engineering Research Institute, California, CA, USA, 2012.

[116] A. S. Elnashai, J. J. Boomer, C. I. Baron, D. Lee, and A. I. Salama, Selected Engineering Seismology and Structural Engineering Studies of the Hyogo-Ken-Nanbu (Great Hanshin) Earthquake of 17 January 1995, London, 1995.

[117] National Seismological Center, Recent Earthquakes, Online https://www.seismonepal.gov.np/, 2015. 